\title{
DIDÁTICA E PRÁTICAS DE ENSINO: INTERLOCUÇÃO COM A EDUCAÇÃO BÁSICA NA FORMAÇÃO INICIAL DE PROFESSORES
}

\author{
DIDACTICS AND TEACHING PRACTICES: AN INTERLOCUTING WITH BASIC \\ EDUCATION IN INITIAL TEACHER TRAINING
}

\begin{abstract}
DIDÁCTICA Y PRÁCTICAS DE ENSEÑANZA: INTERLOCUCIÓN CON LA EDUCACIÓN BÁSICA EN LA FORMACIÓN INICIAL DE PROFESORES
\end{abstract}

\author{
Pura Lúcia Oliver Martins \\ Joana Paulin Romanowski ${ }^{* *}$ \\ Simone Regina Manosso Cartaxo
}

\begin{abstract}
Resumo: Esse texto apresenta reflexões sobre a formação pedagógica do professor nas novas propostas para os cursos de licenciatura. Tem por objetivo analisar a formação inicial de professores no contexto das reformulações desses cursos em relação às prioridades estabelecidas e as implicações com as práticas pedagógicas desenvolvidas na educação básica. Apoia-se no resultado de uma investigação desenvolvida pelo grupo de pesquisa Práxis Educativa: dimensões e processos, vinculado ao Programa de Pós-graduação em Educação da PUCPR que tomou como objeto de estudo a interlocução das disciplinas pedagógicas - Didática e Prática de Ensino - com as práticas pedagógicas desenvolvidas nos anos iniciais do Ensino Fundamental. A metodologia, de abordagem qualitativa utilizou para coleta de dados a análise documental e entrevistas semiestruturadas com coordenadores de curso e professores das disciplinas. Cursos de licenciaturas de três universidades da cidade de Curitiba-PR constituíram o campo da investigação. Na categorização dos dados foi utilizado o software Atlas T.I, e as análises tomam como referência as categorias de conteúdo de Bardin (2009). O aporte teórico inclui Gatti (1997, 2009), Bernardo (1997), Santos (2005), Martins (2003), Romanowski (2002), entre outros. O estudo mostra que a relação didática - práticas de ensino assume diferentes orientações nas instituições investigadas: (i) organização pelo eixo da pesquisa como elemento articulador da formação; (ii) organização pelo eixo interdisciplinar; (iii) organização a partir do campo disciplinar priorizando os fundamentos teóricos para em seguida apontar as teorias que compõem as disciplinas. No conjunto das disciplinas examinadas verifica-se que raramente ocorre a indicação da sua interlocução com a escola básica e suas práticas. O estudo, além de mostrar as especificidades e as articulações possíveis da Didática e da Prática de Ensino neste momento histórico, propõe ampliar a interlocução com a Educação Básica, ultrapassar o eixo epistemológico da teoria como guia da ação predominante na organização curricular dos cursos de licenciaturas e trabalhar com a concepção da teoria como expressão da prática.
\end{abstract}

Palavras-chave: Didática. Prática de Ensino. Educação Básica. Licenciatura. Formação Pedagógica.

Abstract: This paper presents some reflections on teacher pedagogical training on new proposals for undergraduate courses. It aims to analyze the initial formation of teachers in the context of

\footnotetext{
*Doutora em Educação pela USP. Prof ${ }^{a}$ da PUC-PR. Email: pura.oliver@pucpr.br

** Doutora em Educação pela USP. Prof ${ }^{a}$ da PUC-PR. Email: joana.romanowski@gmail.com

*** Doutora em Educação pela USP. Prof ${ }^{a}$ da Rede Municipal de Ensino de Curitiba e da Universidade Estadual de Ponta Grossa. Email: simonemcartaxo@hotmail.com
} 
reformulations of these courses on the priorities established and the implications with the pedagogical practices developed in Basic Education. It is based on the results of an investigation carried out by the research group Práxis Educativa: dimensions and processes linked to the Postgraduate Program in Education of PUCPR that took as object of study the interlocution of the pedagogical courses - Didactics and Teaching Practice - with the pedagogical practices developed in the initial years of Elementary Education. The methodology, of qualitative approach, used as data the documentary analysis and semi-structured interviews with course coordinators and professors. Undergraduate courses at three universities in the city of Curitiba-PR constituted the field of research. In the categorization of the data, the software used was Atlas T.I, and the analyzes take as reference the categories of content of Bardin (2009). The theory study includes Gatti (1997, 2009), Bernardo (1997), Santos (2005), Martins (2003), Romanowski (2002), among others. The study shows that the didactic relationship between teaching and practice assumes different orientations in the investigated institutions: (i) organization by the research axis as an articulating element of the formation; (ii) organization by the interdisciplinary axis; (iii) organization from the disciplinary field prioritizing the theory foundations to then point out the theories that make up the courses. In the set of the examined courses it is verified that it seldom occurs an interlocution with the Basic School and its practices. The study, besides showing the specificities and possible articulations of Didactics and Teaching Practice in that historical moment, proposes to broaden the dialogue with Basic Education to go beyond the epistemological axis of theory as a guide to the predominant action in the curricular organization of undergraduate courses and work with the conception of theory as an expression of practice.

Keywords: Didactics. Teaching practice. Basic Education. Undergraduate Courses. Pedagogical Training.

Resumen: Ese texto presenta reflexiones sobre la formación pedagógica del profesor en las nuevas propuestas para los cursos de licenciatura. Tiene por objetivo analizar la formación inicial de profesores en el contexto de las reformulaciones de eses cursos en relación a las prioridades establecidas y las implicaciones con las prácticas pedagógicas desarrolladas en la educación básica. Se apoya en el resultado de una investigación desarrollada por el grupo de pesquisa Praxis Educativa: dimensiones y procesos, vinculado al Programa de Pos-graduación en Educación de la PUCPR que tomó como objeto de estudio la interlocución de las disciplinas pedagógicas - Didáctica y Práctica de Enseñanza - con las prácticas pedagógicas desarrolladas en los años iniciales de la Enseñanza Fundamental. La metodología, de abordaje cualitativa utilizó para coleta de datos el análisis documental y entrevistas semi-estructuradas con coordinadores de curso y profesores de las disciplinas. Cursos de licenciaturas de tres universidades de la ciudad de Curitiba-PR constituyeron el campo de la investigación. En la categorización de los datos fue utilizado el softwere Atlas T.I, y los análisis toman como referencia las categorías de contenido de Bardin (2009). El aporte teórico inclui Gatti (1997, 2009), Bernardo (1997), Santos (2005), Martins (2003), Romanowski (2002), entre otros. El estudio muestra que la relación didáctica-prácticas de enseñanza asume diferentes orientaciones en las instituciones investigadas: (i) organización por el eje de la pesquisa como elemento articulador de la formación; (ii) organización por el eje interdisciplinar; (iii) organización a partir del campo disciplinar priorizando los fundamentos teóricos para en seguida apuntar las teorías que componen las disciplinas. En el conjunto de las disciplinas examinadas se verifica que raramente ocurre la indicación de su interlocución con la escuela básica y sus prácticas. El estudio, además de mostrar las especificidades y las articulaciones posibles de la Didáctica y de la Práctica de Enseñanza en este momento histórico, propone ampliar la interlocución con la Educación Básica, ultrapasar el eje epistemológico de la teoría como guía de la acción predominante en la organización curricular de los cursos de licenciaturas y trabajar con la concepción de la teoría como expresión de la práctica.

Palabras-clave: Didáctica. Práctica de enseñanza. Educación Básica. Licenciatura. Formación pedagógica. 


\section{Introdução}

As discussões, estudos e pesquisas sobre a formação pedagógica do professor dos vários níveis de ensino têm ocupado cada vez mais espaço entre os formadores de professores, as escolas que recebem esses professores e os estudiosos da área, no Brasil e em outros países, como dizem Nóvoa (2009), Marcelo (1999), Marcelo e Vaillant (2012), Mercado Maldonado (2010), TentiFanfani (2005). São desafios que se intensificam na medida em que assumem o compromisso com a escola pública, laica, gratuita e de qualidade.

Compreendemos qualidade não sob a orientação econômico-produtiva segundo a qual se impõe o desenvolvimento de competências para o trabalho, mas em uma perspectiva histórica de luta pela ampliação da educação como direito, ou seja, uma educação gratuita, laica e organizada pelos princípios democráticos e da coletividade.

Nessa perspectiva, ao discutirmos a formação de professores, almejamos pensar o processo didático que viabiliza o ensino e a aprendizagem num processo de interação entre os sujeitos e os objetos do conhecimento. Consideramos que o ensino reúne elementos articuladores que envolvem o professor, o estudante e o conhecimento em um amplo contexto que é determinante e também determinado pelos sujeitos.

Assim sendo, colocamos em discussão as especificidades e articulações da Didática e da Prática de Ensino no currículo da formação inicial de professores como necessária e urgente. Consideramos também que a formação dos professores precisa ter como centralidade a escola a partir dos problemas da própria prática docente. Entendemos que as ações formativas centralizadas na universidade precisam ser remetidas às demandas sociais da escola básica, ultrapassando, desta forma, os limites em que se encontram as licenciaturas.

Estudos já realizados sobre a didática na formação de professores (MARTINS 2003; 1996) mostram que os professores dos diferentes níveis de ensino, para fazerem frente aos problemas de sua prática pedagógica, decorrentes da contradição entre sua formação inicial e a realidade que encontram nas escolas onde atuam, tomam iniciativas, criam possibilidades de trabalho denominadas de "didática prática”. Essa "didática prática”, captada e sistematizada teoricamente, poderá servir de pistas, de indicação de novas possibilidades de trabalho para os professores. Com esse olhar, pesquisas vinculadas ao grupo de pesquisa "Práxis educativa: dimensões e processos" têm se dedicado a estabelecer um diálogo com os professores da escola básica e também com professores formadores a fim de captar pistas que possam dar consistência às discussões sobre os processos formativos.

Nesses estudos nos apoiamos na concepção de Martins (2003) de que a didática sistematizada na literatura da área é a expressão de uma prática pedagógica que decorre de determinado tipo de relação social no interior do modo de produção que a sustenta. Para a autora, as formas como as classes sociais se relacionam se materializam em técnicas, processos, tecnologias, inclusive os processos pedagógicos que se realizam através de uma dada relação entre professor, aluno e conhecimento. Desse ponto de vista, a reconstrução do conhecimento da área não se faz por meio de reflexões exclusivamente teóricas, mas emerge das contradições presentes na prática de nossas escolas, expressando a prática de seus agentes ao vivenciarem essas contradições.

Nessa perspectiva, a didática não se traduz como guia da ação prática, como pretendem os manuais e os cursos de formação 
inicial de professores, mas, ao contrário, é entendida como expressão de uma prática determinada, num momento histórico determinado. Nesse sentido, as formas de organização, execução e avaliação do processo de ensino expressos nos livros da área, em vez de terem o papel de guia para a ação prática, servem de "explicação" e "justificativa" das práticas que ocorrem no interior da escola.

Isso porque, em tal concepção de didática, o eixo central está nas relações sociais, e a base epistemológica compreende a teoria como expressão da prática, resultante de uma relação que é ao mesmo tempo material e social. Martins (2003) explica que essa prática é material porque se dá no local de trabalho, nas ações concretas da produção da própria vida das pessoas; independe dos pensamentos, das representações. É social porque essa produção não se faz de forma individual, mas coletivamente. Os homens estabelecem relações entre si, estabelecidas no processo de produção. Essa prática não é direta, mas se realiza em instituições que os homens criam na sua ação transformadora, mediante situações práticas. A propósito, João Bernardo $(1977,86)$ escreve:

Uma teoria é sempre a teoria de uma prática e não de qualquer realidade material que transcende o processo dessa prática, nem dessa realidade enquanto não praticada. $\mathrm{O}$ homem não reflete sobre o mundo, mas reflete a sua prática sobre o mundo.

Desse ponto de vista, consideramos importante discutir a necessidade da articulação dos cursos de licenciatura com a realidade, com os problemas, dilemas e alternativas buscadas pelos professores de Educação Básica, na prática, para desenvolver o seu ensino. Então, uma questão se coloca: estariam os cursos de formação inicial de professores, no nível das licenciaturas, buscando estabelecer uma interlocução com a realidade da escola básica? Se sim, como essa articulação se manifesta?

Assim, para encaminhar a reflexão sobre o tema proposto, trazemos para discussão os resultados de uma pesquisa que teve como objetivo analisar a formação inicial de professores no contexto das reformulações dos cursos de licenciatura em relação às prioridades estabelecidas e as implicações com as práticas pedagógicas desenvolvidas no nível básico da educação.

Para o estudo da dimensão prática da formação de professores em cursos de licenciatura, consideramos que a compreensão de um fenômeno exige ir além da sua manifestação aparente, contemplando sua especificidade, as relações e as contradições que a produzem. Para tanto, desenvolvemos uma investigação de natureza qualitativa sobre a dimensão prática da formação dos professores. Ao tratar da dimensão prática tem-se a clareza da necessária superação da concepção fragmentada entre teoria e prática como instâncias estanques, de modo que os estágios podem ser considerados como uma dimensão privilegiada da prática, mas comportam sempre uma dimensão teórica. O estudo pautou-se na concepção de que o que importa não é a crítica pela crítica, mas a crítica que permita uma compreensão dos determinantes de uma dada prática sobre a realidade, possibilitando alterá-la e transformá-la, tanto no nível do conhecimento quanto no nível histórico-social. Além disso, entendemos que o conhecimento se dá na e pela práxis, expressando a unidade entre as duas dimensões do conhecimento, ou seja, teoria e prática.

Nessa perspectiva, o eixo epistemológico orientador do estudo é a concepção de que a teoria é a expressão de uma determinada prática e não de qualquer prática. Nesse paradigma, a prática não é dirigida pela teoria, mas a teoria vai expressar a ação prática 
dos sujeitos. São as formas de agir que vão determinar as formas de pensar dos homens. "A teoria pensa e compreende a prática sobre as coisas, não a coisa. Daí, a sua única função é indicar caminhos possíveis, nunca governar a prática” (BRUNO 1989,18). A base do conhecimento é a ação prática que os homens realizam através de relações sociais, mediante instituições. Dessa forma, “... o conhecimento é sempre o conhecimento de uma prática, nunca da realidade natural ou social.” (SANTOS 1992, 29). Com esse olhar, procuramos ultrapassar as reflexões acadêmicas que se materializam em relações sociais unilaterais, verticalizadas e individualista e que, na maioria das vezes, estão distanciadas dos problemas que a prática pedagógica desenvolvida nas escolas enfrenta.

A investigação teve como campo de estudo três universidades da cidade de Curitiba - Paraná, de natureza jurídica diversa: pública, privada e confessional, que oferecem cursos de licenciatura em diferentes áreas do conhecimento. O material para a pesquisa tomou como referência as disciplinas de Didática e Prática de Ensino de cursos de Licenciatura oferecidos por essas instituições. Além da análise dos documentos, foram realizadas entrevistas com coordenadores dos cursos e professores formadores das disciplinas selecionadas. Ao todo foram analisados 18 cursos de licenciatura, e os dados foram organizados com a utilização do software de análise de dados qualitativos ATLAS.TI, aplicando para a análise dos documentos coletados as etapas de análise de conteúdo definidas por Bardin (2009). As análises foram feitas de forma horizontal focalizando as disciplinas pedagógicas e também uma análise transversal dos conhecimentos trabalhados em cada disciplina.

Ressaltamos que o estudo ora apresentado faz parte de uma investigação mais ampla. Nesta reflexão buscamos conhecer se ocorre a interlocução entre os cursos de formação inicial de professores, no nível das licenciaturas, e a realidade da escola básica e como ela se estabelece.

Para encaminhar a reflexão sobre o objeto em estudo, inicialmente trazemos uma breve contextualização das disciplinas pedagógicas na formação inicial de professores nos cursos de licenciatura. Em seguida focalizamos as aproximações e distanciamentos das disciplinas Didática, Prática de Ensino, Estágio Supervisionado, integrantes dos currículos dos cursos com a prática desenvolvidas nas escolas de Educação Básica. Finalizamos tecendo algumas considerações apontando as possibilidades e limites da interlocução entre o Ensino Superior e a Educação Básica na formação de professores.

\section{As disciplinas pedagógicas na formação inicial de professores nos cursos de licenciatura: breve contextualização}

Os cursos de formação de professores, no Brasil, desde a sua criação em meados do século XIX, com os cursos normais para formar os professores para o ensino primário e, em 1934, com os cursos de Licenciatura, têm sua organização definida pelos órgãos governamentais. A organização e a prática realizada nestes cursos, especialmente nas licenciaturas, apresentam-se com inúmeros problemas, como apontados por pesquisas, estudos e análises realizadas, nas últimas décadas.

Ressalta-se que os estados da arte sobre a pesquisa em formação de professores realizados por André e Romanowski (1999) apontam poucos estudos sobre a formação pedagógica do professor considerando a proposta do curso em sua totalidade, à medida que se observa, na maioria, a referência a uma disciplina. Soma-se a isso o que é recorrente 
nas pesquisas e estudos da área: a formação pedagógica do professor é pouco valorizada nos cursos de licenciatura.

As pesquisas dos anos de 1990 corroboram as críticas e denúncias realizadas desde a década de 1980 sobre os cursos de licenciatura, que indicam a permanência da estrutura universitária departamentalizada impedindo discussões coletivas para a superação das dicotomias existentes.

Com efeito, nem mesmo as reestruturações institucionais têm possibilitado uma articulação orgânica desses cursos, e, em alguns casos, essa reestruturação tem diminuído e restringido a inclusão dos professores da área pedagógica na sua definição curricular, agravada pela expansão com diminuição de custos, como aponta Taffarel (1993).

A consolidação desta estrutura mantém estes cursos híbridos e desintegrados (GATTI, 1997) evidenciando a permanente dicotomização, pela forma como os cursos se organizam em dois momentos distintos: conteúdos específicos e conteúdos pedagógicos. Ou seja, a própria estrutura curricular em que os espaços das instituições formadoras e os da iniciação profissional realizada nos estágios se mantêm distanciados e estanques, aliados à estrutura de departamentalização, acabam impossibilitando a organicidade e identidade de uma formação articulada com as prioridades e finalidades da Educação Básica.

Observa-se, então, que a prática pedagógica, os procedimentos e processos metodológicos dos professores dos cursos de licenciatura, resistem em promover inovações, pois a realização da pesquisa e reflexão nos processos de formação não é evidenciada. A propósito, a pesquisa de Lüdke (1994) ao examinar as licenciaturas destaca, como questões desafiadoras que dificultam a implementação de novas propostas, quais sejam: o modelo de Universidade existente que não valoriza nem estimula em seu interior a formação de professores; a existência de uma hierarquia entre os cursos no interior da instituição; o afastamento entre as escolas do ensino básico e a universidade; a desintegração entre as diferentes áreas de formação. Essas são questões recorrentes nas pesquisas examinadas, o que indica que as inovações realizadas nestes cursos não produzem uma alteração na reformulação do curso em totalidade ainda que inegavelmente sejam inovações importantes embora parciais.

Com o Parecer 09/2001 (BRASIL, 2001) e as Resoluções 01/2002 e 02/2002 (BRASIL, $2002 \mathrm{ab}$ ), do Conselho Nacional de Educação, orienta-se uma nova proposta para os cursos de formação de professores não atrelada ao bacharelado, mas a ele articulada, o que significou um novo rumo para estes cursos. No entanto, ao valorizarem as competências no perfil profissional dos professores, acentuam a formação técnica. Além disso, a ampliação da carga horária de prática de ensino a ser desenvolvida no decorrer do curso representou a possibilidade de uma nova configuração dos cursos, o que vem exigindo um acompanhamento pelos pesquisadores avaliando a implementação destas mudanças.

Dias da Silva (2005) aponta aspectos centrais destas Resoluções do Conselho Nacional de Educação (CNE), em que a implantação nos cursos de licenciaturas pode ter resultado na negação do papel formador que cabe à área de Educação, decorrentes da banalização e/ou negação do conhecimento educacional. Nas palavras da autora (2005, p. 6):

A questão central passou a ser aritmética: impregnados por uma cultura organizacional legalista, acostumada ao estabelecimento de currículos mínimos para cursos de graduação, aliada aos eternos embates bacharelado \&licenciatura, o resultado 
imediato dessas resoluções para nossas universidades se reduziu ao loteamento de horas na grade curricular, com consequências desastrosas para a construção do conhecimento dos futuros professores (DIAS DA SILVA, 2005, p. 6).

Com efeito, estudo desenvolvido por Romanovski e Martins (2009) em três universidades da cidade de Curitiba mostrou que a forma de encaminhamento da reestruturação dos cursos de licenciatura é bastante diversificada. Inclui a constituição de uma coordenação específica para a reformulação dos cursos em uma das instituições; a definição de oferta de curso específico de licenciatura em algumas áreas favorecendo a constituição identitária do profissional professor; a busca de articulação entre as disciplinas direcionadas a cursos de bacharelado e de licenciatura contribuindo para organicidade da formação do professor; a inclusão de disciplinas de conhecimentos interdisciplinares direcionadas a conhecimentos complementares à formação docente. Essas disciplinas complementares abordam questões como: estudos sobre diversidade cultural; ensino para alunos com necessidades especiais; educação ambiental; disciplinas comuns para todos os cursos de licenciatura, de modo a aproximar os professores dos cursos; ampliação do número de disciplinas direcionadas para a prática profissional específica de docência; esforço na definição de política para a realização do estágio de docência buscando estabelecer parcerias consolidadas com escolas da comunidade.

Por outro lado, esse estudo mostrou também fortes indícios de que o esforço para estabelecer atividades e disciplinas comuns pode estar direcionado à possibilidade de manter a oferta dos cursos de licenciaturas em função da pouca procura por eles. A criação de disciplinas comuns ao bacharelado e licenciaturas, muitas vezes, pode estar ligada ao melhor aproveitamento dos professores juntando turmas de um ou mais cursos. Nesse sentido, há indícios de que a modulação das disciplinas pedagógicas, em especial a Prática de Ensino, foi alterada ampliando o número de alunos por professor.

\section{Didática, Prática de Ensino e Educação Básica: aproximações e distanciamentos}

Formar professores para a Educação Básica favorecendo a articulação da realidade desse nível de ensino com os estudos no nível da Educação Superior é um desafio que vem de longa data. Essa preocupação foi muito intensa na década de 1980, período fecundo na produção de conhecimento tendo como foco a aproximação necessária com a realidade das escolas onde os futuros professores irão atuar.

Estudo de Martins e Romanowski (2009) traz um mapeamento dos grupos de pesquisa que investigam a formação pedagógica de professores e as produções de teses e dissertações nos programas de pós-graduação em Educação na primeira década deste século e mostra que, nos anos iniciais, as pesquisas que fazem referência à articulação da formação inicial de professores com a prática pedagógica desenvolvida nas escolas básicas é pequena. Registra-se, no entanto, uma tendência de crescimento dessa discussão nos últimos três anos. A escola básica, seus dilemas e problemas práticos, volta a ocupar espaço nas pesquisas e produções acadêmicas da área.

A análise das propostas de formação pedagógica do professor no contexto das reformulações dos cursos de Licenciatura em relação às prioridades estabelecidas e as implicações com a prática pedagógica desenvolvida na escola básica revela que as universidades investigadas encaminham suas proposições de maneira diferenciada (MARTINS; 
ROMANOWSKI, 2009). Ainda que em todas elas haja indícios de articulação das disciplinas pedagógicas, especialmente Didática e Prática de Ensino, com a prática desenvolvida nas escolas, as análises das ementas e programas das disciplinas indicam que a Educação Básica, seus problemas e práticas, tem sido focada mais como campo de desenvolvimento de atividade pelos acadêmicos do que como espaço para problematização e análise crítica da prática pedagógica e suas condições objetivas de trabalho.

Uma das universidades investigadas tem como eixo orientador da sua proposta de curso a pesquisa da prática pedagógica como elemento articulador da formação e é realizada desde os anos iniciais do curso. A proposta da organização do curso é estruturar e desenvolver as disciplinas que compõem a formação pedagógica dos licenciandos, a partir desse contato com escola básica. Isso indica uma tentativa de articulação das disciplinas de formação com as escolas onde os futuros profissionais da educação irão atuar. As ementas e programas examinados deixam clara essa proposição, à medida que se verifica nas disciplinas de Didática e Prática de Ensino a proposta dessa aproximação com a realidade e a prática pedagógica desenvolvida na Educação Básica. Há uma tentativa de problematizar a prática desenvolvida nas escolas de Educação Básica tendo em vista a compreensão dos problemas da prática pedagógica e das iniciativas dos professores para superá-los, mesmo que, ainda, na organização curricular dos cursos essas disciplinas estejam situadas nos períodos finais do curso.

Já a outra universidade pesquisada toma, como eixo orientador da organização de seus cursos, os Fundamentos da Educação e a relação Teoria e Prática, que permeiam quase todas as disciplinas de forma articulada. Nesta instituição, a interdisciplinaridade é o elemento articulador da formação.
Curiosamente, não se verifica qualquer referência à Educação Básica e suas práticas, ainda que a relação entre teoria e prática esteja no centro da proposta dos cursos. Observa-se que essa relação cinge-se à universidade e não se estende à Educação Básica como campo teórico-prático de formação. O contato com o campo de trabalho limita-se à disciplina de Prática de Ensino e se faz pela aplicação da teoria no campo da prática nos períodos finais dos cursos.

A terceira universidade investigada organiza os cursos a partir do campo disciplinar e prioriza os fundamentos teóricos para em seguida apontar as teorias que compõem as disciplinas. Considerando o conjunto dos cursos, verifica-se que a categoria fundamentos incide com maior intensidade tanto nos Fundamentos da Educação, propriamente ditos, como na disciplina Didática. Embora se configure como fundamentos, a abordagem refere-se, na maioria das licenciaturas, aos fundamentos da epistemologia da ciência, específica de cada curso. Destaca-se a perspectiva histórica nas disciplinas de Fundamentos da Educação e no curso de Pedagogia. Nessa universidade, no conjunto das disciplinas examinadas, verifica-se que raramente ocorre a indicação da relação destas com a escola básica e suas práticas. Há uma priorização dos fundamentos teóricos entendendo que essa formação teórica sólida resultará em uma prática consequente.

Quanto à prática profissional presente em todos os cursos analisados, ela se refere aos fundamentos da prática, mas não necessariamente à ação docente. Já em relação aos espaços escolares, focalizam-se algumas das disciplinas do curso de Pedagogia, especificamente em Currículo e Estágio Supervisionado, como estar no espaço escolar desenvolvendo atividades. Não se trata de análise desse espaço. 
Com efeito, o estudo mostra, em que pese as diferenças entre as instituições analisadas, um ponto comum que se mantém inalterado. Considerando nosso foco de reflexão proposto inicialmente - o de conhecer se ocorre a interlocução entre os cursos de formação inicial de professores, no nível das licenciaturas com a prática desenvolvida na escola básica e como ela se estabelece -, identificamos que os cursos são perpassados pelo eixo epistemológico da teoria como guia da prática priorizando a formação teórica. Observa-se que o pressuposto básico de que uma sólida formação teórica garante uma prática consequente, conforme Martins (2003), ainda é o que prevalece na organização dos cursos.

\section{Considerações Finais}

Trabalhando com o eixo epistemológico da teoria como expressão da prática, entendendo que as iniciativas dos professores da Educação Básica constituem saberes importantes para a Didática e a Prática de Ensino enquanto campo disciplinar na formação inicial de professores, procuramos investigar se os cursos de licenciatura têm estabelecido uma interlocução com a prática da Educação Básica e como ela se manifesta.

A análise das propostas de formação pedagógica do professor no contexto das reformulações dos cursos de licenciaturas em relação às prioridades estabelecidas e as implicações com a prática pedagógica desenvolvida na escola básica revela que em todas elas há indícios de articulação das disciplinas pedagógicas, especialmente Didática e Prática de Ensino, com a prática desenvolvida nas escolas de Educação Básica, ainda que o encaminhamento de suas proposições seja feito de maneira diferenciada.

Desse modo, verificamos que cada instituição coloca em destaque algum aspecto no processo formativo: (i) quando o elemento articulador do curso está na pesquisa da prática pedagógica desde o início do curso, na organização curricular ainda se mantêm as práticas de ensino situadas nos semestres finais; (ii) a instituição, ao priorizar a docência e a prática pedagógica com a observação, participação e docência na sala de aula, expressa nas disciplinas do núcleo integrado de fundamentos educacionais e nas metodologias de ensino específicas, verifica-se, contudo, o entendimento da escola de Educação Básica e suas práticas pedagógicas como campo de aplicação da teoria; (iii) em alguns cursos observa-se que as práticas contêm conhecimentos sobre a área específica e não sobre a docência. Destarte no conjunto das instituições pesquisadas a relação com a escola de Educação Básica e suas práticas cinge-se às disciplinas específicas de Estágio e Prática de Ensino que também ocorrem no final do curso.

Com efeito, o estudo mostra que, em que pesem as diferenças entre as instituições analisadas, um ponto comum se mantém inalterado. Os cursos são perpassados pelo eixo epistemológico da teoria como guia da prática e, portanto, com um foco maior na aquisição teórica.

Dessa forma, a articulação da Didática e Prática de Ensino com a Educação Básica, nas três universidades investigadas está presente em graus e formas diferentes. A organização dos cursos pelo eixo da pesquisa como elemento articulador da formação é um indicador forte da aproximação e parceria entre a universidade e a escola de Educação Básica. Não obstante, ainda é predominante a ênfase na formação teórica tanto na organização curricular apoiada no eixo articulador da interdisciplinaridade quanto na organização do currículo a partir do campo disciplinar. 
A relação com a escola de Educação Básica ainda fica restrita ao campo da Prática de Ensino e do Estágio Supervisionado cuja lógica é de aplicação das teorias veiculadas nas diferentes disciplinas que compõem o currículo, especialmente a Didática.

O desafio que permanece para a formação inicial de professores nos cursos de licenciatura é ampliar e resignificar a interlocução desses cursos com a prática pedagógica, dentro de determinadas condições objetivas de trabalho, que ocorre no interior das escolas de Educação Básica. Em outros termos, ultrapassar o eixo epistemológico da teoria como guia da ação, predominante na organização curricular dos cursos de licenciatura e trabalhar com a concepção de teoria como expressão da prática. Fazer do campo da educação básica um espaço de problematização, de análise crítica e sistematização dos conhecimentos produzidos por seus agentes no enfrentamento dos problemas decorrentes da contradição entre a formação acadêmica recebida e a realidade da escola onde atuam. Eis o nosso desafio!

\section{Referências}

ANDRÉ, M. E. D. A. de; ROMANOWSKI, J. P. O tema formação de professores nas teses e dissertações brasileiras, 1990-1996. In: REUNIÃO Anual da ANPEd, 22., 1999, Caxambu (MG). Anais... Caxambu: ANPEd, 1999.

BARDIN, L. Análise de conteúdo. 2. Ed. São Paulo: Edições 70, 2009.

BERNARDO, J. Marx crítico de Marx. Porto, Editora Afrontamento, 1977..

BRASIL. Ministério da Educação. Conselho Nacional de Educação. Conselho Pleno. Resolução CNE/CP n ${ }^{\circ}$ 1, de 18 de fevereiro de 2002. Diário Oficial da União, Brasília,
DF, 9 abr. 2002a. Seção 1, p. 31-32. Disponível em: <http://portal.mec.gov.br/ cne/ arquivos/pdf/rcp01_02.pdf $>$. Acesso em: 10 dez. 2013.

. Ministério da Educação. Conselho Nacional de Educação. Conselho Pleno. Resolução CNE/CP n 2, de 19 de fevereiro de 2002. Diário Oficial da União, Brasília, DF, 4 mar. 2002b. Seção 1, p. 9-10. Disponível em: <http://portal.mec.gov.br/ cne/ arquivos/pdf/CP022002.pdf>. Acesso em: 10 dez. 2012.

.Parecer 09, de 08 de maio de 2001. Diretrizes curriculares para a formação inicial de professores da educação básica em cursos de nível superior. Disponível em: $<$ http://portal.mec.gov.br/cne/arquivos/pdf/ 009.pdf>. Acesso em: 12 set. 2009.

BRUNO, L. Acerca do indivíduo, da prática e da consciência da prática. In: Educação e Sociedade n. 33(7-27), São Paulo, Cortez, Ago/1989

DIAS-DA-SILVA, M. H. G. F. Política de formação de professores no Brasil: as ciladas da reestruturação das licenciaturas. Perspectiva. Florianópolis, v. 23, n. 02, p. 381-406, jul./dez. 2005

GATTI, B. Formação de professores e carreira. São Paulo: Cortez, 1997.

LÜDKE, M. Avaliação institucional: formação de docentes para o ensino fundamental e médio (as licenciaturas). Série: Cadernos CRUB. v. 1, n. 4, 1994.

MARCELO, C. (1999). Formação de professores para uma mudança educativa. Porto: Porto Editora.

MARTINS, P. L. O. A relação conteúdoforma: expressão das contradições da prática pedagógica na escola capitalista. In: VEIGA, Ilma Passos Alencastro (Org.). Didática: o 
ensino e suas relações. Campinas: Papirus, 1996.

\section{A didática e as contradições}

da prática. $2^{\mathrm{a}}$. Ed. Campinas $-\mathrm{SP}$, Papirus Editora, 2003.

MERCADO MALDONADO, R. Un debate actual sobre la formación inicial de docentes en México. Psicol. Esc. Educ. (Impr.), Campinas, v. 14, n. 1, p. 149-157, jun. 2010. Disponible en <http://www.scielo.br/ scielo.php?script=sci_arttext\&pid=S141385572010000100016\&lng $=$ es \&nrm $=$ iso $>$. accedido en 06 agosto 2014. http://dx.doi. org/10.1590/S1413-85572010000100016.

NÓVOA, A. Para una formación de professores construida dentro de la profesión. Revista de Educación, Madrid, 350 p. 203218. Sep.-dic. 2009.

ROMANOWSKI, J. P.; MARTINS, P. L. O.; GISI, M. L. As disciplinas pedagógicas nos cursos de licenciatura: tensões e prioridades. Curitiba, 2009. Relatório de pesquisa.

SANTOS, O. J. Pedagogia dos conflitos sociais. Campinas-SP, Papirus, 1992.

TAFFAREL, C. N. Z. A formação do profissional da educação: o processo de trabalho pedagógico e o trato com o conhecimento no curso de Educação Física. Campinas. Tese (Doutorado em Educação) Universidade Estadual de Campinas, 1993.

TENTI FANFANI, E. La Condición Docente: Análisis comparado de $\mathrm{La}$ Argentina, Brasil, Peru y Uruguay. Buenos Aires: Siglo XXI Editores Argentina, 2005.

VAILLANT, D.; MARCELO, C. (2012). Ensinando a ensinar: As quatro etapas de uma aprendizagem. 1.ed. Curitiba: Ed. UTFPR. 